\title{
Coarse and fine filters, gap analysis, and systematic conservation planning
}

\author{
by Louis-Vincent Lemelin ${ }^{1}$ and Marcel Darveau²
}

\begin{abstract}
This paper compares the principal concepts and methodologies that have been developed in conservation planning over the past few decades. Of these, the terms coarse filter and fine filter have been used inconsistently, we propose, therefore, consensual grounds for a definition. The term "gap analysis" has been used to refer to the prescriptive methodology of Gap Analysis and the latter is not consensual among conservation biologists. Nevertheless Gap Analysis has contributed greatly, along with the systematic conservation planning methodology, to the development of conservation planning. Overall, conservation planning has proved sound enough to merit interest and involvement from forest managers.
\end{abstract}

Key words: coarse filter, fine filter, gap analysis, systematic conservation planning, ecological representation, protected areas

\section{RÉSUMÉ}

Cet article compare les principaux concepts et méthodologies mis de l'avant au cours des dernières années en planification de la conservation. Les filtres brut et fin ont été utilisés selon des visions divergentes; des définitions consensuelles sont donc proposées. L'expression «analyse de carence» a été employée pour décrire une méthodologie normative (Gap Analysis), qui ne fait pas consensus au sein des biologistes de la conservation. Néanmoins, cette méthodologie et celle de la planification systématique de la conservation ont largement contribué au développement de la planification de la conservation. Globalement, la planification de la conservation s'avère suffisamment fondée pour susciter l'intérêt et l'implication de la part des aménagistes forestiers.

Mots clés : filtre brut, filtre fin, analyse de carence, planification systématique de la conservation, représentation écologique, aires protégées

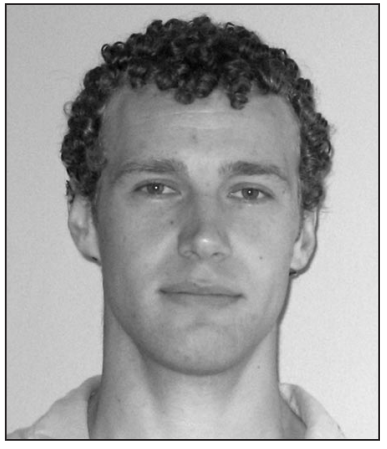

Louis-Vincent Lemelin

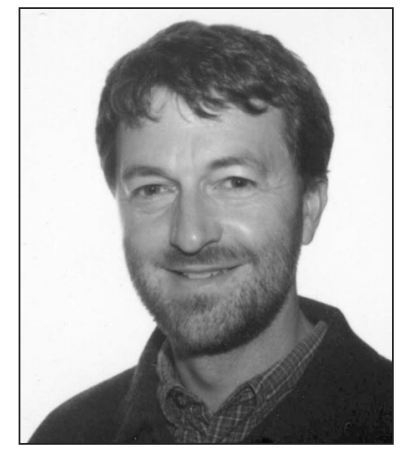

Marcel Darveau

\section{Introduction}

Over the past few decades, several planning methods have been developed in an effort to systematize biodiversity conservation in protected areas. The different paths taken to develop conservation planning have led to a variety of new concepts and terminology including coarse filter, fine filter, gap analysis, and systematic conservation planning. These concepts are nevertheless interrelated as they all comply to the

general and widely accepted goal of ecological representation. Two questions are addressed in this paper: (1) what is the current consensus on these concepts? and (2) what are the differences, similarities and links regarding their application? The paper concludes with a brief discussion about the integration of conservation planning theories into forest management, with the example of the boreal forest.

\section{Conservation by Coarse and Fine Filters}

The coarse filter and fine filter concepts originate from the branch of conservation biology that addresses nature reserve networks planning, or conservation planning. Whereas the fine filter concept has been more focussed over time, the coarse-filter concept has proved more susceptible to changes. In this section, we briefly review the origins of the coarse- and fine-filter concepts and discuss how they have evolved with regard to their implementation. We conclude by suggesting a common definition from which the use of both coarse and fine filters can be developed further.

The conservation of biodiversity is generally considered the primary objective of a conservation planning strategy. In the early 1980s, in order to take into account biodiversity at all levels, the agency The Nature Conservancy (TNC) developed

\footnotetext{
${ }^{1}$ Registered Professional Forester. Département des sciences du bois et de la forêt, Université Laval, Québec (Québec) G1K 7P4 and Ducks Unlimited Canada, 710 Bouvier, Bureau 260, Québec (Québec) G2J 1C2. E-mail: 1_lemelin@ducks.ca. (address to which correspondence should be sent) Current address: Unité d'enseignement et de recherche en sciences appliquées, Université du Québec en AbitibiTémiscamingue, 445 boulevard de l'Université, Rouyn-Noranda (Québec) J9X 5E4.

${ }^{2}$ Registered Professional Forester, Ph.D. Ducks Unlimited Canada, 710 Bouvier, Bureau 260, Québec (Québec) G2J 1C2 and Centre de recherche en biologie forestière, Université Laval, Québec (Québec) G1K 7P4. E-mail: m_darveau@ducks.ca.
} 
a system to inventory, evaluate, and protect elements of biodiversity at vegetation community and species levels. This system was commonly illustrated as a metaphor for the two filters: coarse filter for the community level and fine filter for the species level (Noss 1987). The coarse filter, as originally presented by Noss, implied the conservation of a representative sample of each type of natural community inventoried; it was expected that about $85 \%$ to $90 \%$ of the species could be protected using this filter. The fine filter was viewed as a complementary approach that would capture, on an individual basis, threatened or endangered species that had fallen through the coarse filter. While it was understood that a fine filter would address endangered species concerns through active management, a coarse filter was clearly intended to guide biodiversity conservation through the establishment of conservation areas.

The coarse filter concept was then examined by Hunter et al. (1988), who critically questioned its efficiency and who saw it as a broader approach. Their criticisms emphasized that the goal of the coarse-filter approach should focus on species rather than communities and that, in an evolutionary time scale, stable communities do not hold more importance than rare, transitory, or loosely organized ones. Moreover, because of the short interglacial period occurring in the northern part of North America and Eurasia, natural communities are not, at least in those areas, the final product of a long coevolution, but rather the preliminary result of recent colonization. A further criticism was that the prediction of $85 \%$ to $90 \%$ for the efficiency of coarse filter was too optimistic. Finally, Hunter et al. (1988) suggested that the coarse-filter approach would be more efficient if the target was to maintain a diversity of environments rather than a diversity of natural communities. Where species-environment relations are too complex they suggest an approach that highlights the diversity of ecosystems. The protected areas would then be considered as "arenas" for biological activity (Hunter et al. 1988). According to Wilcove (1989), these criticisms did not invalidate the coarsefilter approach, although they somewhat weakened the effectiveness of natural communities as the basis of the approach.

During the 1990s, the use of the coarse filter approach was taken up by resource-exploited areas and the concept became incorporated into a more comprehensive debate surrounding the necessary levels of diversity to consider in biodiversity conservation. In particular, management of the habitat requirements for umbrella species, such as the northern spotted owl (Strix occidentalis), has been referred to as a coarse-filter approach (Tracy and Brussard 1994), the umbrella species becoming a "coarse-filter species" (Franklin 1994). Further adaptations of the coarse-filter approach also include the representation of ecological units based upon historic variability of the natural landscape either through identification of minimum-threshold levels in ecosystem management (Haufler et al. 1996) or through socially and economically acceptable levels in natural disturbance-based forest management (Bergeron et al. 2002). These examples of the coarse-filter approach in areas with management priorities other than biological conservation distance themselves from what was — and still is for many (e.g., Hunter 2005) — understood by the term "coarse-filter approach," i.e., as a method for conservation planning.
As a whole, we conclude that the coarse filter has been used to describe a wide variety of approaches to biological conservation, and that there is no consensus about its definition among the scientific community. However, we can highlight a general trend among the so-called coarse-filter approaches that could be a basis for a definition based on both usage and rationale. Indeed, most users relied on the following hypothesis saying that, for a given area and as long as all of the components are adequately classified and represented, there is one or a few ecological resolutions, or ecological scales, that can act as a surrogate for the vast majority of the biological diversity, of all organization levels. We suggest that this hypothesis be the definition of the coarse filter principle. Consequently, every conservation approach based on this hypothesis could be referred to as a coarse-filter approach. To illustrate this with the aforementioned examples, the surrogate levels were: the community types for TNC (Noss 1987), the species for biodiversity (as a first surrogacy step) and the environmental types for the species (as a second step) for Hunter et al. (1988), the set of habitat requirements of the northern spotted owl for Tracy and Brussard (1994), the vegetation types and growth stages for Haufler et al. (1996), and both the forest cohorts and the spatial configuration of the landscapes for Bergeron et al. (2002). Evidently, there is no consensus regarding the use of the coarse-filter approach as seen with the variety of levels of protection (from preservation to active management) and territory designations (from reserve to densely populated areas). Furthermore, even though ecological organization levels used as surrogates are generally described at coarse scales, coarse scale should not be confused with coarse filter (e.g., Schwartz 1999). For example, efforts aimed at conserving a rare and endangered ecosystem type in spite of adequate environmental diversity conservation would not correspond to coarse-filter conservation. If one accepts the definition we suggest above, these efforts would in fact logically correspond to a fine-filter conservation approach. Again, this view of the fine filter departs from the original view, proposed by Noss (1987), of a method exclusively dedicated to species.

Whereas coarse-filter conservation objectives aim to "ensure representation" (of the constituents of a particular ecological level), the fine-filter conservation objectives are more precise to "saving (a biological entity) from extinction." Therefore, the challenges of a coarse- and fine-filter approach lie with identifying the most efficient levels of surrogacy, inventorying and classification, finding the most appropriate way to conserve all of their parts, and monitoring for efficiency and fine-filter cases. Finally, the relative importance of resource allocation regarding coarse versus fine filters is a fundamental issue that integrates both scientific and societal considerations (Franklin 1993, 1994; Orians 1993; Tracy and Brussard 1994).

In summary, the coarse-filter principle - as formulated in the above lines - seems to be widely accepted by the scientific community and to have become a paradigm in ecosystem management and conservation planning. Alongside which, multiple variants based on the general representation principle have been proposed, including Gap Analysis and systematic conservation planning methodologies. 


\section{Gap Analysis, and Systematic Conservation Planning}

In 1993, Scott et al. put forward the basis for an elaborated methodology that analyzes biodiversity representation gaps in conservation networks, an approach they called Gap Analysis. An important conservation program based on this methodology was then set up in the United States, under the name of Gap Analysis Program (GAP). Basically, the method compares the distribution of targeted taxonomic groups of vegetation types and species across an area with the protected areas that it contains (Jennings 2000). This highlights the under-representation of biodiversity features in the network of protected areas, the results of which include, apart from gap identification, maps of existing vegetation types and predicted species distribution, and can subsequently be used to orientate future conservation actions. As a sort of coarse-filter approach, Gap Analysis uses vegetation types and species of targeted taxonomic groups as surrogates for overall biodiversity. Therefore, much of the criticism of the original coarse filter definition (sensu Noss 1987) applies to Gap Analysis as well. What is generally agreed upon in the context of conservation planning is the use of gap analysis in the broad sense of the term, i.e., a task that consists of identifying conservation gaps by relying on ecological representation principles and taking into account the existing protected areas, in order to subsequently fill those gaps with the implementation of new conservation measures. Nevertheless, those developing the notion of Gap Analysis have contributed significantly to conservation planning theories and application.

In parallel, systematic reserve selection methodologies have been developed and applied in other countries, such as Australia, where researchers have been particularly prolific (Kirkpatrick 1983; Margules et al. 1988; Pressey and Nicholls 1989a, b; Nicholls and Margules 1993; Pressey et al. 1993; Pressey 1994; Ferrier et al. 2000; Margules and Pressey 2000). Systematic reserve selection generally considers three basic principles: complementarity, flexibility, and irreplaceability of the territorial units. These principles are directed at minimizing the total reserve area needed to achieve the conservation goals (Pressey et al. 1993). Using a combination of algorithmic and geomatic processes, systematic reserve selection tries to identify the smallest set(s) of territorial units that will satisfy the conservation goals, expressed in terms of representativeness, or representation, of biological features. The results could eventually become integrated into decision support tools for global systematic conservation planning.

Overall, we could see a gap analysis being an integral first part of systematic conservation planning. Indeed, the three first "stages" of the approach, as described by Margules and Pressey (2000), consist of 1) compiling data on the biodiversity of a region, 2) identifying conservation goals for the region, and 3) reviewing the existing protected areas. In addition though, the conservation planning process is completed by three more stages, namely: 4 ) selecting new sets of areas to be protected, 5) implementing conservation actions, and 6) maintaining the required values of the conservation areas. Another particularity of systematic conservation planning is the methodology explicitly states that the decisions taken about the ecological surrogacy levels and data should be specific with regard to the planning region (Margules and Pressey 2000).

\section{Biodiversity Surrogates Where Data Are Scarce}

The use of surrogates seems to be unanimously accepted by the scientific community. However, there is currently a lively debate about the choice of the ecological surrogacy levels to consider when setting up representation goals. In areas where data on species distribution are scarce, such as for most of the Canadian boreal forest, the debate is simplified and the remaining alternatives fall into three categories: 1 ) vegetation communities, 2) abiotic or environmental units, and 3) ecosystems. Vegetation communities and environmental conditions convey a certain amount of common information because to some extent vegetation communities depend on environmental characteristics. In spite of the debate surrounding the advantages and the disadvantages of each category, it is clear that pragmatic solutions are tenable once zoning has been performed: both vegetation and environment should therefore be used as surrogates when available (Pressey and Logan 1994), thus supplementing information on ecological diversity.

\section{Forest Managers and Conservation Planning}

For forest managers, conservation planning is complementary to ecosystem-based forest management and conservation areas are a piece of the overall forest management picture. This last section tries to give a few insights on why and how forest managers should and could realize conservation planning by examining some common characteristics of boreal forest management.

In many areas, forest management represents an important cause of ecological alteration, if not the most important. Furthermore, for various reasons, forest managers frequently wish to mitigate their environmental impacts and attain high environmental standards. These are key reasons for which forest managers should play a leading role in conservation planning, even though it is rather the obligation of the authorities. Fortunately, with conceptual and methodological developments such as coarse and fine filters, gap analysis, and systematic conservation planning, conservation science has proven to be sound enough to justify its application in most contexts.

With their experience in the field, forest managers benefit from a relatively good knowledge of their forest management area (FMA). Therefore, they have an important role to play around the table with other specialists involved in land and water conservation planning and implementation. Certain specialists from government agencies and non-governmental organizations are concerned with a variety of different scales, giving all parties involved in the planning an opportunity to consider biodiversity and conservation at multiple scales. A coordinated approach, such as this, is also necessary to bring together different views, resulting in a greater acceptance of ideas and more efficient results (Groves 2003).

As mentioned earlier, the boreal forest is a vast domain where data on biodiversity are generally scarce. As a result the coarse-filter approach is often applied at the ecoregion scale $\left(\sim 100000 \mathrm{~km}^{2}\right)$ without the fine-filter to complement because no data are available at a finer scale (Lemelin and Darveau 2005). Nevertheless, more finer-scale work, which still relies on the coarse-filter principle, might also be appropriate. For example, the FMAs in Quebec, that cover an aver- 
age of $500 \mathrm{~km}^{2}$, are operational divisions at which a coarsefilter approach, i.e., an approach aimed at ensuring that the elements of a classification system are well represented, could efficiently complement a broader scale (Breton and Darveau 2005).

\section{Conclusion}

To summarize, it is clear from the scientific debates and developments that the conservation of biodiversity is too complex to apply a single approach. As far as possible one must consider the preservation of populations, species, communities, physical environments, ecosystems, and landscapes (Hunter et al. 1988, Sarkar and Margules 2002), proceed with the best data available, select appropriate methodologies with regard to the area in question and existing knowledge, and involve multiple specialists in the planning process. For the forest manager, careful conservation planning constitutes an interesting way with which to go above and beyond the legal environmental requirements.

\section{Acknowledgments}

Thoughtful comments from two anonymous reviewers greatly contributed to improve this manuscript. The authors also wish to thank Judith Kirby for editorial assistance.

\section{References}

Bergeron, Y., A. Leduc, B.D. Harvey and S. Gauthier. 2002. Natural Fire Regime: A Guide for Sustainable Management of the Canadian Boreal Forest. Silva Fenn. 36: 81-95.

Breton, M.N. and M. Darveau. 2005. Projet pilote de conservation des milieux humides et riverains dans un territoire où niche le Garrot d'Islande. Rapport technique No Q2005-2. Canards Illimités Canada - Québec, Québec. 65 p.

Ferrier, S., R.L. Pressey and T.W. Barrett. 2000. A New Predictor of the Irreplaceability of Areas for Achieving a Conservation Goal, its Application to Real-world Planning, and a Research Agenda for Further Refinement. Biol. Conserv. 93: 303-325.

Franklin, J.F. 1993. Preserving Biodiversity: Species, Ecosystems, or Landscapes? Ecol. Appl. 3: 202-205.

Franklin, J.F. 1994. Preserving Biodiversity: Species in Landscapes: Response. Ecol. Appl. 4: 208-209.

Groves, C.R. 2003. Drafting a Conservation Blueprint. Island Press, Washington, D.C. 457 p.

Haufler, J.B., C.A. Mehl and G.J. Roloff. 1996. Using a Coarse-filter Approach with Species Assessment for Ecosystem Management. Wildl. Soc. Bull. 24: 200-208.

Hunter, M.L. Jr. 2005. A Mesofilter Conservation Strategy to Complement Fine and Coarse Filters. Conserv. Biol. 19: 1025-1029.
Hunter, M.L., Jr., L.J. George Jr. and T. Webb III. 1988. Paleoecology and the Coarse-Filter Approach to Maintaining Biological Diversity. Conserv. Biol. 2: 375-385.

Jennings, M.D. 2000. Gap Analysis: Concepts, Methods, and Recent Results. Landsc. Ecol. 15: 5-20.

Kirkpatrick, J.B. 1983. An Iterative Method for Establishing Priorities for the Selection of Nature Reserves: An Example From Tasmania. Biol. Conserv. 25: 127-134.

Lemelin, L.V. and M. Darveau. 2005. Analyse de la prise en compte des hydrosystèmes de la forêt boréale par la Stratégie québécoise sur les aires protégées. Rapport technique No Q2005-4. Canards Illimités Canada - Québec, Québec. 71 p.

Margules, C.R., A.O. Nicholls and R.L. Pressey. 1988. Selecting Networks of Reserves to Maximise Biological Diversity. Biol. Conserv. 43: 63-76.

Margules, C.R. and R.L. Pressey. 2000. Systematic Conservation Planning. Nature 405: 243-253.

Nicholls, A.O. and C.R. Margules. 1993. An Upgraded Reserve Selection Algorithm. Biol. Conserv. 64: 165-169.

Noss, R.F. 1987. From Plant Communities to Landscapes in Conservation Inventories: A Look at The Nature Conservancy (USA). Biol. Conserv. 41: 11-37.

Orians, G.H. 1993. Endangered at What Level? Ecol. Appl. 3: 206-208.

Pressey, R.L. 1994. Ad Hoc Reservations: Forward or Backward Steps in Developing Representative Reserve Systems? Biol. Conserv. 8: 662-668.

Pressey, R.L., C.J. Humphries, C.R. Margules, R.I. Vane-Wright and P.H. Williams. 1993. Beyond Opportunism: Key Principles for Systematic Reserve Selection. Trends Ecol. Evol. 8: 124-128.

Pressey, R.L. and V.S. Logan. 1994. Level of Geographical Subdivision and Its Effects on Assessments of Reserve Coverage: A Review of Regional Studies. Conserv. Biol. 8: 1037-1046.

Pressey, R.L. and A.O. Nicholls. 1989a. Application of a Numerical Algorithm to the Selection of Reserves in Semi-arid New South Wales. Biol. Conserv. 50: 263-278.

Pressey, R.L. and A.O. Nicholls. 1989b. Efficiency in Conservation Evaluation: Scoring versus Iterative Approaches. Biol. Conserv. 50: 199-218.

Sarkar, S. and C. Margules. 2002. Operationalizing Biodiversity for Conservation Planning. J. Biosci. 27: 299-308.

Schwartz, M.W. 1999. Choosing the Appropriate Scale of Reserves for Conservation. Ann. Rev. Ecol. Syst. 30: 83-108.

Scott, J.M., F. Davis, B. Csuti, R. Noss, B. Butterfield, C. Groves, H. Anderson, S. Caicco, F. D'Erchia, T.C. Edwards Jr., J. Ulliman and R.G. Wright. 1993. Gap Analysis: A Geographic Approach to Protection of Biological Diversity. Wildl. Monogr. 123: 1-41.

Tracy, C.R. and P.F. Brussard. 1994. Preserving Biodiversity: Species in Landscapes. Ecol. Appl. 4: 205-207.

Wilcove, D.S. 1989. Protecting Biodiversity in Multiple-use Lands: Lessons from the US Forest Service. Trends Ecol. Evol. 4: 385-388. 